\title{
Optimization of Drying Process of Rambutan by Combined Method of Osmosis Ultrasound and Complementary Drying of Hot Air
}

\author{
Muhammad Farooq ${ }^{*}$, Elham Azadfar ${ }^{2}$, Zohre Bahrami $^{3}$, Mahniya Sharifi $^{3}$, A. Shakoor ${ }^{4}$, Shabir Ahmed ${ }^{5}$ \\ Iftikhar Ahmed Solangi ${ }^{1}$, Muhammad Noman Khan ${ }^{6}$, Memona Siddique ${ }^{7}$, Naila Ilyas ${ }^{8 *}$, Muhammad \\ Bakhtiar', Mohamed El-Fatieh Ismael ${ }^{1}$ and Wang Yunyang ${ }^{1}$
}

${ }^{1}$ College of Food Science and Engineering, Northwest A and F University, Yangling, Shaanxi 712100, PR China; ${ }^{2}$ Young Researchers, and Elites Club, Sabzevar Branch, Islamic Azad University, Sabzevar, Iran; ${ }^{3}$ Department of Food Chemistry, Sabzevar Branch, Islamic Azad University, Sabzevar, Iran; ${ }^{4}$ Beijing Key Laboratory of Quality Evaluation Technology for Hygiene and Safety of Plastic, Beijing Technology and Business. University, Beijing, 100048, China, ${ }^{5}$ Assistant Director Food, Zhob Baluchistan, Pakistan; ${ }^{6}$ Department of Horticulture, The University of Agriculture Peshawar, Pakistan; ${ }^{7}$ Department of Plant Pathology, Bahauddin Zakariya University, Multan, Pakistan; ${ }^{8}$ Graduate School of Chinese Academy of Agricultural Sciences, Bejing 100081, China; ${ }^{9}$ Department of Agronomy, University of Agriculture Peshawar, Pakistan.

Abstract | Drying is widely known to be one of the common processes in the food industry to increase the shelf life of fruits and vegetables. Using osmosis-ultrasound before drying with hot air causes the preservation of nutrients in products and reduces heat energy to remove the produc water. In this study, after osmosis pretreatment, samples were put under an osmosis dehydration process. First, using Osmosis-ultrasound with $40.5 \%$ concentration in Sekanjabin solution then dried in an oven at a temperature of $70^{\circ} \mathrm{C}$. The characteristics of solid gain, water and weight loss, shrinkage and rehydration were evaluated. The obtained results showed that by increasing the concentration of weight and water loss, solid gain increased. Accordingly, in a higher concentrated osmotic solution, the osmotic pressure, which is a key factor in mass transfer in the osmotic dehydration process, increases by increasing concentration, the percentage of solids gain increased; shrinkage and rehydration decreased. Conclusively, the drying of Rambutan by use of osmosis-ultrasound dehydration process when compared to osmotic dehydration, showed a significant decrease in the shrinkage of fruits resulting in rehydration, i.e., causing the percentage of solid gain, weight and water loss to be increased.

Received | November 04, 2020; Accepted | January 14, 2021; Published | March 06, 2021

*Correspondence | Muhammad Farooq and Naila Ilyas, College of Food Science and Engineering, Northwest A and F University, Yangling, Shaanxi 712100, PR China; Graduate School of Chinese Academy of Agricultural Sciences, Bejing 100081,China; Email: Farooq.fst28@gmail. com, wyy10421@163.com

Citation | Farooq, M., E. Azadfar, Z. Bahrami, M. Sharifi, A. Shakoor, S. Ahmed, I.A. Solangi, M.N. Khan, M. Siddique, N. Ilyas, M. Bakhtiar, M. El-Fatieh Ismael and W. Yunyang. 2021. Optimization of drying process of rambutan by combined method of osmosis ultrasound and complementary drying of hot air. Pakistan Journal of Agricultural Research, 34(1): 218-226.

DOI | http://dx.doi.org/10.17582/journal.pjar/2021/34.1.218.226

Keywords | Rambutan, Water loss, Solid gain, Osmosis, Ultrasound

\section{Introduction}

$\mathrm{D}$ rying of fruits has been considered as a way to improve the durability, and is one of the main methods which have been common for centuries. Unlike fresh vegetables which are kept only for a short period of time and in special circumstances, dried products can be kept a long time without reducing the nutritional value. Also, because of the low mass weight of dried fruits, they are easily and conveniently transported (Da Silva et al., 2017). The fruit used in this research for drying is Rambutan which is native to Southeast Asia, i.e., Malaysia, Indonesia and Thailand. In the Malay language, Rambutan means 
"hairy" derived from the hairy look of the fruit's skin. Rambutan is of the Sapindaceae family, known scientifically as Nephelium lappaceum is a tropical fruit (Mokhtar et al., 2019; Sun et al., 2012).

Rambutan fruit is sweet, juicy, tastes like a grape and has a big core. Its fruit looks a lot like Lychee and Longan. Rambutan fruit is almost spherical and hairy. Thailand is the largest producer of Rambutan with 588.000 tons $(55.5 \%)$ in 2005 , followed by Indonesia with 320,000 tons (30.2\%) and Malaysia with 126.300 tons (11.9\%). These three countries have a total of $97 \%$ of the world's Rambutan supply. Rambutan needs a tropical climate of, about $22-30^{\circ} \mathrm{C}$, and a temperature below $10^{\circ} \mathrm{C}$ to produce fruits. The Rambutan tree is native to the tropics, isn't deeply rooted, bears fruits 2 to 3 years after planting and fruiting ability is 8 to 10 years. Rambutan is rich in vitamin $\mathrm{C}$ and calcium, and is a good source of magnesium and potassium; in smaller amounts iron and fibre Azarpazhooh and Ramaswamy (2010).

To increase its conservation some methods such as canning, fermentation and freeze drying can be used. Among these methods, freeze drying produces a product of the highest quality, but is one of the most expensive methods. So, a simple and inexpensive method with low investment is required to increase the preservation of most perishable goods, and will be available for all consumers far from cultivated areas. Osmotic drying is one of these methods. Osmotic drying is one method of food preservation which can create better qualitative properties in the product. In the osmotic process, due to limited short time use of hot airflow to complete drying, not only does the desirable features of the product be preserved, but also, the need for heat energy deeply decreases to remove additional water from the product. Osmotic dehydration is used as a pre-process of some drying methods such as drying with hot air, vacuum drying, frying, canning and freezing. The basis of the drying process using the osmotic method is the placement of pieces of food in a hypertonic solution (sugar, salt or mixture of sugars and salts solution). These solutions typically have higher osmotic pressure and lower water activity when compared to the cellular environment of food. Since the cell wall of many foods can act as a semi-permeable membrane, then the driving force for water movement between the nutrient and osmotic solution is created. Of course, this wall won't act completely selective and a sometimes dissolved solid in the osmotic liquid is leaked into the food. The Osmotic drying process is a multi-component mass transfer process, where the release of water from food simultaneously with solids in the osmotic solution, permeates into the tissue, i.e., the cells or intercellular spaces. Also, amounts of intercellular solution were removed from the sample and inserted into the osmotic solution (Maskouki et al., 2007).

Pre-treatment of ultrasound waves were used in this research. The use of ultrasound waves causes an increase in the penetration factor of moisture and reduces the drying process time. Ultrasound waves made by the cavitation phenomenon, create a series of rapid contractions and expansions, which is like pressing and releasing a sponge, and cause the withdrawal of water from the solid matrix, and on the other hand create micro-channels to facilitate mass transfer during drying by hot air (Maskouki et al., 2007). Drying with ultrasound is of high commercial importance. In this method, food is damaged less and dries with less moisture content. In this research, the combined pre-treatments of osmotic dehydration process with ultrasound in the drying process of Rambutan by hot air are reviewed. The goal of this study is to prepare a dried product of Rambutan with desirable qualitative features.

\section{Materials and Methods}

Sekanjabin: the product of Kimiya Khorasan was purchased from local market Iran. Sekanjabin one of the oldest Iranian drinks, is made of honey and vinegar. Sekanjabin is usually served in summer. It is sometimes seasoned with mint.

\section{Preparation}

Fresh Rambutan fruit was purchases from the local market in Iran. was refrigerated at $4^{\circ} \mathrm{C}$ until test time, to reduce the respiratory and biological activities of microbes. Rambutan was washed and peeled at the beginning of the test.

\section{Osmotic debydration and ultrasound}

In this study, Sekanjabin syrup was used as an osmotic environment. The concentration of Sekanjabin was selected $40 \%$ to $50 \%$. The temperature of the dehydration process was regulated, fixed and equated to the ambient temperature of $25^{\circ} \mathrm{C}$, throughout the process and in all treatments. The ratio of fruit to the osmotic environment was determined 1:4 (Torreggiani 
and Bertolo, 2004). The tests were performed by the implementation of changing conditions (i.e., mixing the osmotic solution) at an interval of once per hour (Torreggiani and Bertolo, 2001). The fruit pieces were placed at the intervals of 0 and $30 \mathrm{~min}$ under ultrasound pre-process $(25 \mathrm{kHz})$. Then, under the dehydration process without ultrasound. At 120 mins immersion, osmotic solution was continued and the exchange of hot air was performed by using a dryer equipped with an air circulating fan at a fixed temperature of $70^{\circ} \mathrm{C}$ for complementary drying.

\section{Measurement of initial moisture}

Measurement of initial moisture of Rambutan was performed with oven method at a temperature of $105^{\circ} \mathrm{C}$ for 24 hours (AOAC DC, 1990).

Calculation of parameter and the corresponding equations The rate of weight loss (WR), water loss (WL) and solid gain (SG), Rambutan slices were calculated based on their distribution in different stages (before osmotic dehydration, after osmosis and after drying in oven) by Equations 1, 2, 3 .

$$
S G=\frac{\left(m_{t} \times x_{s t}\right)-\left(m_{0} \times x_{s 0}\right)}{m_{0}}
$$

Equation 1: Water loss:

$$
S G=\frac{\left(m_{t} \times x_{s t}\right)-\left(m_{0} \times x_{s 0}\right)}{m_{0}}
$$

Equation 2: Solid gain:

Equation 3: Weight loss:

$$
W R=W L-S G
$$

\section{Shrinkage}

To measure shrinkage, samples were firstly dried in the intended temperature and then shrinkage was determined by the following equation (Zecchi and Gerla, 2020; Sioholm and Gekas, 1995) Equation 4.

$$
\% \mathrm{SKG}=\frac{\mathrm{V}_{\circ}-\mathrm{V}}{\mathrm{V}_{\circ}}
$$

In this equation, $\mathrm{VO}$ - the volume of fresh Rambutan $\left(\mathrm{Cm}^{3}\right)$; V - Volume of Rambutan after drying $\left(\mathrm{Cm}^{3}\right)$; The volume of samples was calculated toluene displacement.

\section{Rebydration}

Rehydration of sample was calculated by relative calculation of the increasing weight of the sample, after 3 hours' immersion in distilled water at the ambient temperature, compared to the weight of the dried sample before immersion at the ambient temperature (Rene and Marin, 2009).

\section{$p H$}

pH was measured by digital pH meter (Model 3510, Jenway manufacturing Company) (8).

\section{Information analysis methods}

This study was conducted in a factorial experiment with three replications. The comparison of Mean was determined using a 5\% level Duncan test, the SAS Software version $9 / 2$ used for variance analysis and drawing charts completed using Excel 2010.

\section{Results and Discussion}

\section{Water loss}

According to Figure 1, concerning the impact of interaction on the concentration and dehydration environment, during osmosis-ultrasound dehydration on water loss in Rambutan fruit, the highest rate of water loss was seen during osmosis dehydrationultrasound in $50 \%$ solution. The results indicated that the interaction of concentration and dehydration environment in osmotic mode is significant at 5\% level. As shown in Figure 1, the samples which were exposed to ultrasound waves had a higher rate of water loss. This phenomenon is due to the creation of micro-channels and ease of water loss by the sample. Ultrasound mechanism was examined, with two cavitation and sponge effect phenomena. Both phenomena affected mass transfer. The results have shown that cavitation has a considerable role in the separation of water connected to food and sponge effect, which causes the formation of microscopic networks that accelerates the drainage of liquid. For this reason, ultrasound increases the efficiency of osmosis (21.4).

The effect of different concentrations of the Sekanjabin osmotic solution, on water loss, showed that it had a significant effect on the water loss in the Rambutan fruit $(\mathrm{P}<0 / 05)$. In reviewing the effect of different concentrations of Sekanjabin osmotic solution, water loss was observed; by increasing the concentration of the osmotic solution, water loss 
was dramatically increased. The highest water loss can be attributed to a high concentration of osmotic solution because osmotic pressure increases in higher concentrations of osmotic solution. As a result of higher osmotic pressure, osmotic moisture loss is more (12). Expressed that the increase of water loss is due to an increase in cell damage and the deformation of cells to outflow moisture from food. Tested the effect of ultrasound on strawberries under osmosis which results indicated that the use of ultrasound caused water loss.

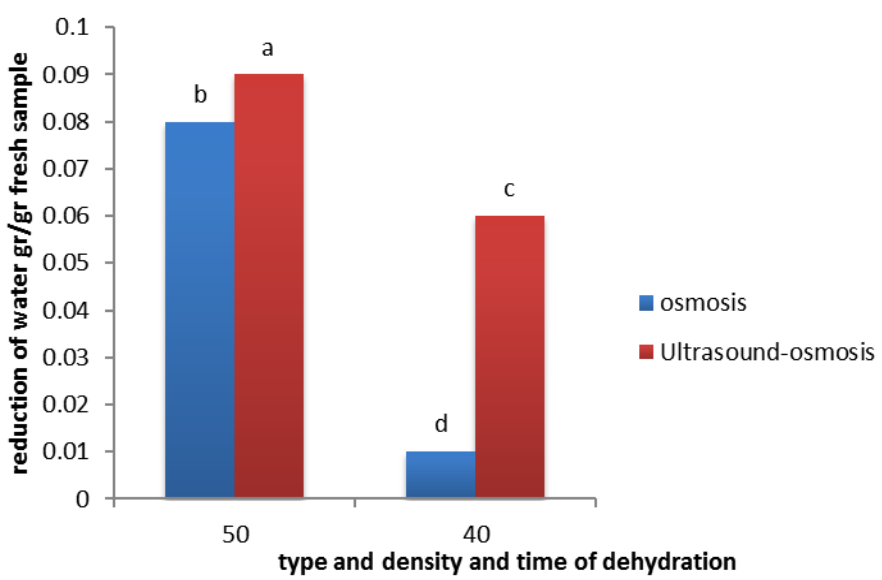

Figure 1: The interaction of concentration and debydration environment on water loss of Rambutan fruit during debydration process.

\section{Solid gain}

According to Figure 2, concerning the interaction of concentration and dehydration environment, during osmosis dehydration and osmosis-ultrasound on the solid gain. The highest rate of solid gain was observed during osmosis-ultrasound dehydration in $50 \%$ solution, for the Rambutan fruit. The results indicated that such interactions of the concentration and dehydration environment in osmotic mode is significant at $5 \%$ level.

Figure 2 further shows that solid gain was increased. Using ultrasound, the highest solid gain in the osmosis-ultrasound mode is at $50 \%$ concentration. By using ultrasound, the solid gain of the osmotic solution increases. Also, due to the microscopic channel, osmosis-ultrasound pre-treatment shows, the existence of solids in $50 \%$ concentration. The solid gain was increased because ultrasound can be attributed to the destruction of the cell membranes, as well as the creation of pores in the cell walls (12). The number of solids in $50 \%$ concentrations has been increased when compared to $40 \%$. By increasing concentration, the intensity of moisture removal is increased; have caused changes in the physical properties of the tissue. This intensifies the penetration of solid molecules, which resulted in an increase of osmotic agents into the tissue. According to statistical reports, the osmosis-ultrasound mode is 0/003 ( $\mathrm{g} / 100 \mathrm{~g}$ solids); has the most solid gain in $50 \%$ concentration. In the osmotic mode it's $0 / 001$ (g / $100 \mathrm{~g}$ solids) in $40 \%$ concentration, the lowest solid gain was observed, $(p<0.05)$; Showing significant difference.

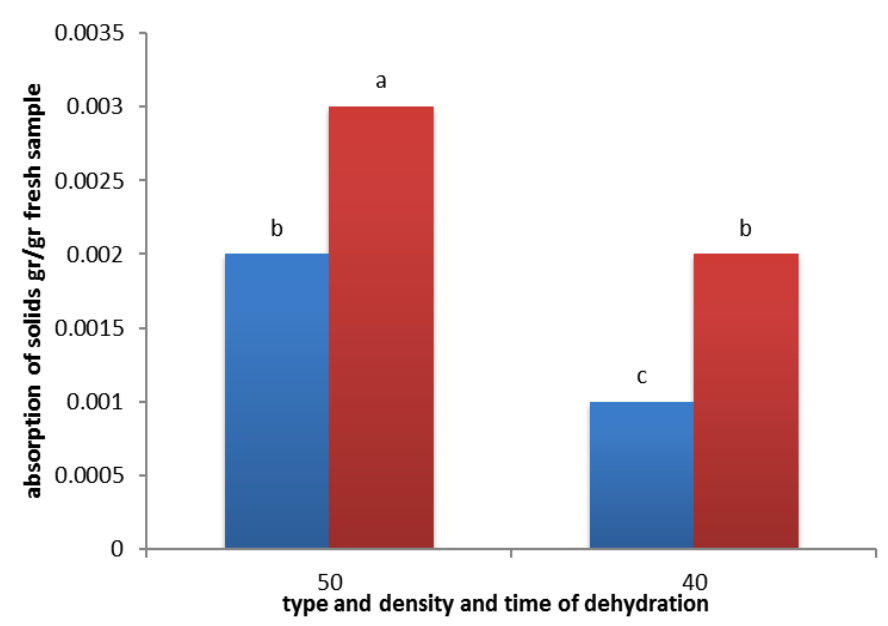

Figure 2: The interaction of concentration and debydration environment on solid gain of Rambutan fruit during debydration process.

Eshraghi et al. (2011) obtained similar results in their studies of the effect of ultrasound pretreatment on drying fresh Kiwi slices. The results showed that absorption increases by intensifying ultrasound. Examined the effect of the immersion time in osmosis and ultrasound, on features of cellular structures of Papaya during dehydration. The results indicated that the destruction of cellular tissue by ultrasound causes an increase in solid gain. Rezagah et al. (2009) showed that solid gain was increased by increasing the osmotic concentration.

\section{Weight loss}

Based on the interaction between the concentration and dehydration environment, during osmosis dehydration and osmosis-ultrasound on weight loss in Rambutan fruit, the highest rate of weight loss was observed, in a $50 \%$ solution of osmosis-ultrasound dehydration. The results indicated that the time, type and concentration of dehydration environment in osmotic mode is significant at 5\% level. Also, the effect of concentration on osmotic dehydration environment at 5\% level was significant to the weight loss of the Rambutan fruit $(\mathrm{P}<0 / 05)$. 
According to Figure 3, weight loss increased by increasing the osmotic solution concentration. Due to the change in pores of cellular structures, ultrasound and osmosis was used, which caused increased water disposal, having a direct relation with weight loss. Based on the interaction of the concentration and dehydration environment, on the weight loss of Rambutan fruit, the highest weight loss was seen in dehydration environment with $50 \%$ concentration and the least in dehydration environment with $40 \%$, showing a significant difference. Using higher concentrations can cause higher dehydration, and consequently, weight loss to increase. The results when compared, found that the average maximum weight loss is related to osmosis-ultrasound dehydration in $50 \%$ solution with an amount of $0 / 087(\mathrm{~g} / \mathrm{g}$ fresh sample) and the least related to $40 \%$ concentration with osmosis dehydration with an amount of $0 / 009$ ( $\mathrm{g} / \mathrm{g}$ fresh sample).

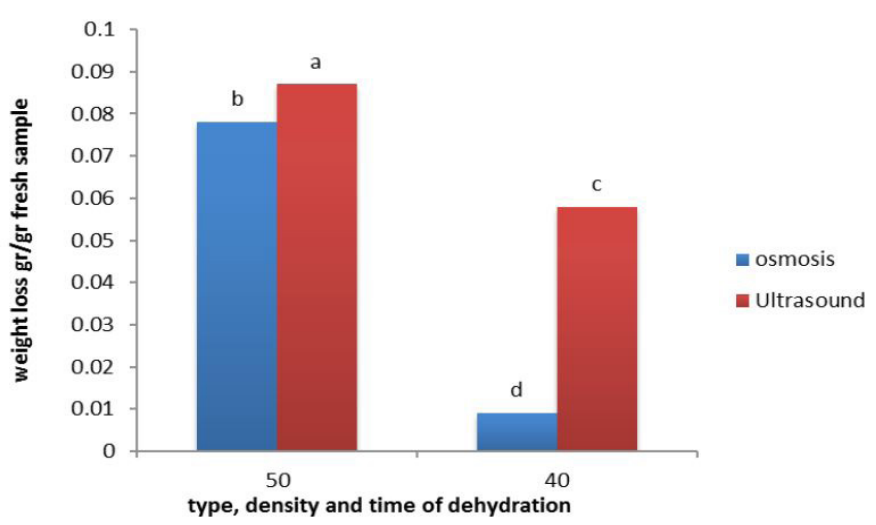

Figure 3: The interaction of time, type and dehydration environment on weight loss of Rambutan fruit during dehydration process.

Maskouki et al. (2007) found that ultrasound alone is not effective in a short time and contact time of the product. The osmotic solution indicated an increase in water removal from the product; as a result of increasing contact time, osmotic agents can be more penetrable in a banana tissue. Which enables added water removal, i.e., more weight loss is observed.

\section{Rebydration}

According to the interaction of the concentration and dehydration environment, during osmosis-ultrasound dehydration on rehydration in Rambutan fruit. The highest rate of rehydration was observed, during osmosis-ultrasound dehydration in 40\% solution with a significant difference in $(\mathrm{P}<0.05)$ level. Such that, according to statistical reports in $40 \%$ concentration and osmosis-ultrasound dehydration of $2 / 55(\mathrm{~g} / \mathrm{g})$, has the most rehydration. Concentration and osmotic mode in $50 \%$, of $1 / 95(\mathrm{~g} / \mathrm{g})$ showed the least rehydration; has a significant difference statistically $(\mathrm{p}<0.05)$.

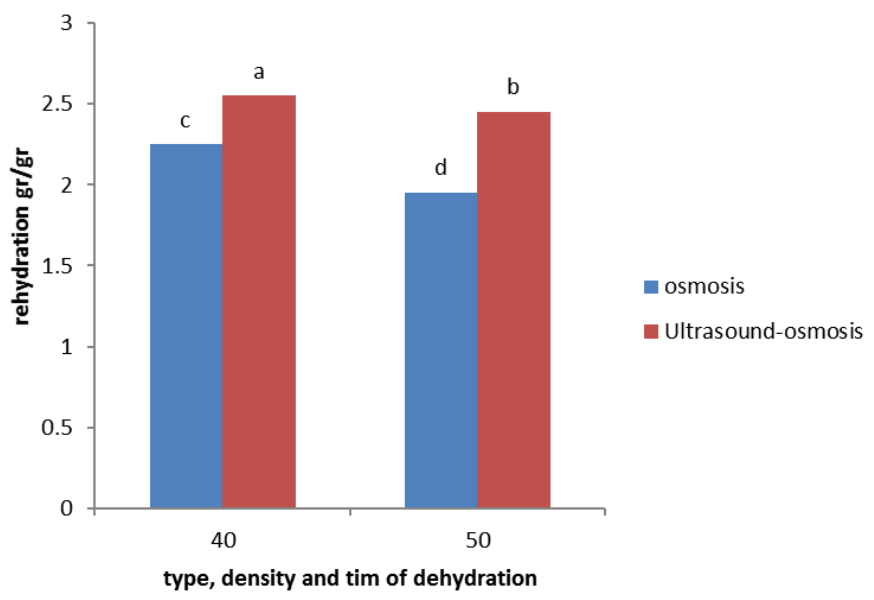

Figure 4: The interaction of concentration and rebydration environment on rehydration of Rambutan fruit during bydration process.

Less rehydration in osmotic mode compared to osmosis-ultrasound is due to solid gain in the osmosis process, in which the rate of rehydration will be decreased by samples. The concentration of the osmotic solution was effective on the rate of rehydration. Ultrasound waves caused an increase in rehydration as compared to osmotic mode (without ultrasound). This is due to the formation of microscopic channels obtained from the cavitation and sponge effect phenomenon. Therefore, dried samples by ultrasound have more porous tissues than dried samples by osmotic solution (without ultrasound) and can show better water absorption (4). Jambrak et al. (2006) used ultrasonic waves to accelerate the drying of Button Mushrooms, Brussels sprouts and Cauliflower. In other words, by increasing ultrasound and creating more microscopic channels resulting from cavitation, the sample has a more porous tissue when compared to the control sample. It can also absorb water better than the control sample; increase the rehydration of the control sample than dried samples with ultrasonic waves.

\section{Shrinkage}

According to the interreaction of the concentration and dehydration environment, during osmosis-ultrasound dehydration on the shrinkage in Rambutan fruit, the highest rate of shrinkage was observed during osmosis-ultrasound dehydration in $40 \%$ solution, i.e., a significant difference in $(\mathrm{p}<0.05)$ level. According to statistics, a $40 \%$ concentration with an osmotic mode of $0 / 87(\mathrm{~g} / \mathrm{g})$ showed the most shrinkage; a $50 \%$ 
concentration with an osmosis-ultrasound mode of $0 / 78(\mathrm{~g} / \mathrm{g})$ the least. This shows a significant statistical difference $(p<0.05)$. The interaction of concentration and dehydration on shrinkage, in Figure 5 of osmosis dehydration, with and without ultrasound, was examined. The maximum shrinkage is under $40 \%$ osmosis concentration. Comparisons between the average shrinkage and different treatments showed that $40 \%$ concentration has the highest shrinkage, as compared to other treatments.

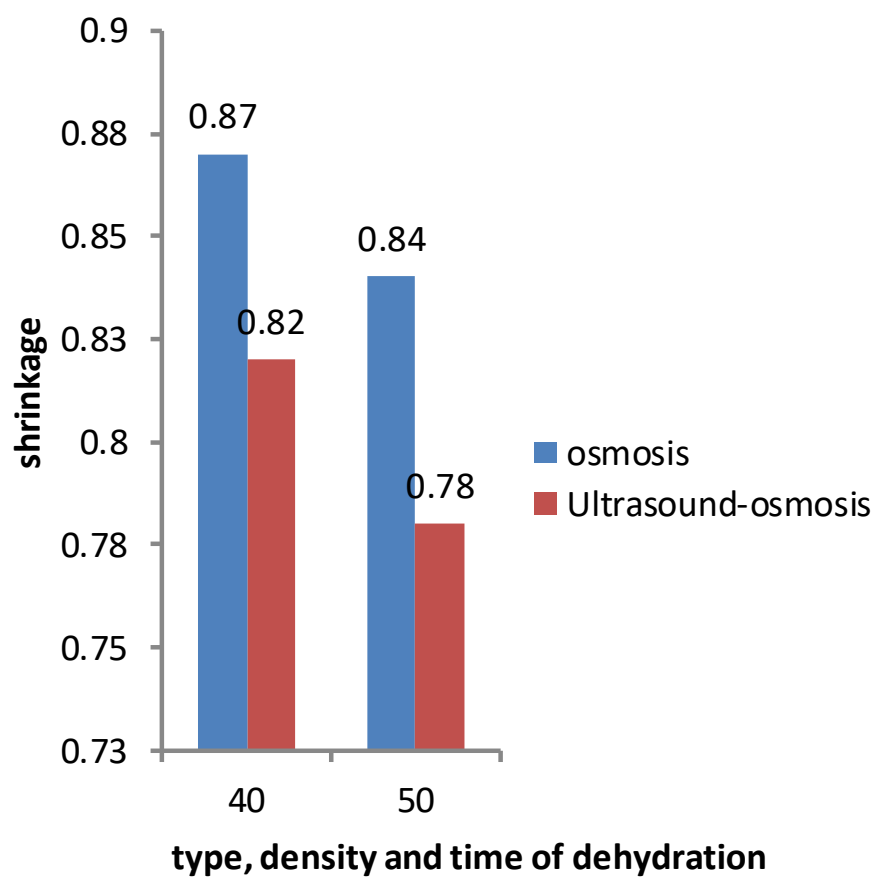

Figure 5: The interaction of concentration and debydration environment on shrinkage of Rambutan fruit during debydration process.

By studying the effect of different concentrations on shrinkage, it was seen that by increasing the concentration, the shrinkage of fruit was significantly increased. As shown in Figure 5, the simultaneous use of ultrasound and osmosis caused the shrinkage's osmosis to lessen; as a result, the creation of microscopic channels by ultrasound. This in-turn makes removing moisture through microscopic channels faster and easier. The placement of the sugar solids (Sekanjabin) into Rambutan using 50\% concentration caused less shrinkage than the $40 \%$ concentration. This is due to the osmotic pressure and the input of more solution solid (Sekanjabin) into the intercellular space of the sample. This has caused the continuity of solution solid while increasing the mechanical resistance of the Rambutan's cellular tissue (5).

The Shrinkage of tissue was directly related to the intensity of the osmosis process. By increasing the solid gain during the osmosis process, the rate of shrinkage was reduced, due to the increase in tissue resistance caused by the penetration of sugar (Solids which penetrate intra-contextual space prevents shrinkage by filling empty spaces and channels). Eshraghi et al. (2011), Shousler et al. (2012) examined that, the use of ultrasound, causes a reduction in shrinkage when compared to the control sample. Ferando and Space (2003) showed that due to the displacement of removed water from strawberry tissue with the absorbed sucrose; by increasing the concentration of a Sucrose osmotic solution, the cell's shrinkage was reduced. Nito et al. (2004) shared further insights on the results obtained in this research.

$p H$

According to the impact of the interaction in the concentration and dehydration environment, during the osmosis-ultrasound dehydration on the $\mathrm{pH}$ in Rambutan fruit, the highest rate was observed during osmosis-ultrasound mode in $40 \%$ solution (Figure 6). The results indicated that the interaction of the concentration and dehydration environment in osmosis-ultrasound mode was significant at 5\% level. Sugar and acid material (acetic acid) was absorbed from the osmotic solution into the tissue of fruit; caused an increase in acidity and a reduction in $\mathrm{pH}$. Absorbed organic acids from the osmotic solution, can cause a reduction in the $\mathrm{pH}$ of the product while reducing the activity of the Phenolase enzyme; the rate of browning. Given that the time of drying samples caused by dehydration with ultrasound was less than osmotic dehydration, the samples were less exposed to the hot air of the oven. Consequently, a lesser amount of sugar remained in the Rambutan fruit; was converted to organic acids in ultrasound. The rate of acidity was reduced in ultrasound, and the pH was increased (5). Eshraghi et al. (2011) stated in their study, on the effect of ultrasound in the drying of fresh kiwi slices, that by increasing the time of ultrasound time taken to reach $20 \%$ moisture was reduced, i.e., drying time was reduced and samples dried in a shorter time period. Investigated that the increasing $\mathrm{pH}$ is associated with an increase of temperature, and drying time by using different temperatures during drying apple fruit roll.

Showed that by drying Rambutan by the dehydration process using the osmosis-ultrasound method as compared to osmotic dehydration, caused a percentage of water loss, solid gain and weight loss to be reduced. By using ultrasound, the shrinkage was reduced, 
and rehydration increased. With an increase in the osmotic concentration weight loss, water loss and solid gain were also increased. Higher concentrations created more osmotic pressure, which caused a faster removal of moisture from the samples. By increasing the concentration, the percentage of solid gain was increased; consequently, shrinkage and rehydration were reduced.

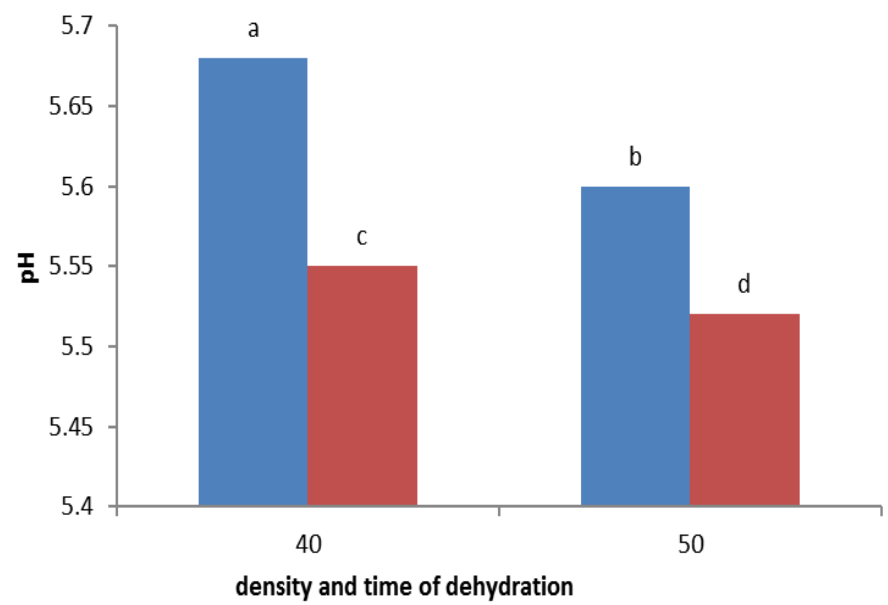

Figure 6: The interaction of concentration and debydration environment of $p H$ of Rambutan fruit during debydration process.

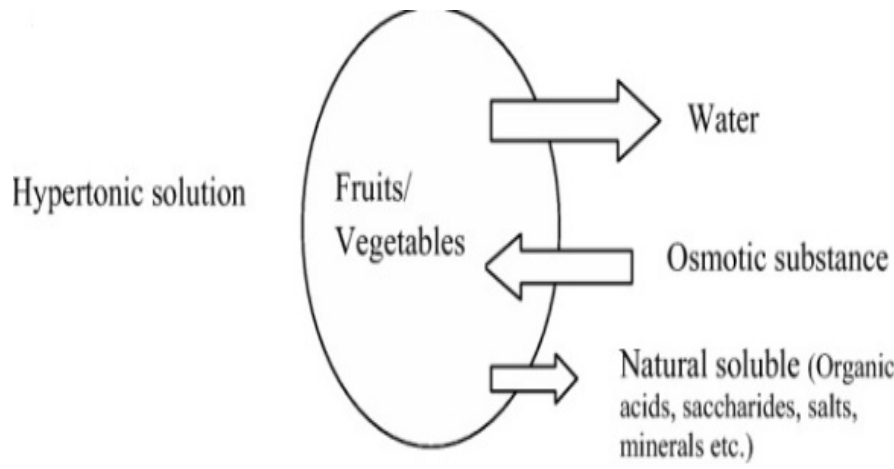

Figure 7: Schematic Diagram of Osmotic dehydration of fruits and vegetables

\section{Conclusions and Recommendations}

In this study, after the osmosis-ultrasound pretreatment, the samples were dried in a hot air oven. Water and weight loss, solid gain, shrinkage and rehydration were evaluated the whole results. The effect of different concentrations of the Sekanjabin osmotic solution, on water loss, showed that it had a significant effect on the water loss in the Rambutan fruits. Pre-treatment of ultrasound waves were used in this research. The use of ultrasound waves causes an increase in the penetration factor of moisture and reduces the drying process time.
Novelty Statement

The present study be unable of reader to understand optimization of combined method of osmosis ultrasound and complementary drying of hot air.

\section{Author's Contribution}

Muhammad Farooq: Original draft.

Elham Azadfar: Discussion.

Zohre Bahramiand Mahniya Sharifi: Material and Methods.

A.Shakoor, Shabir Ahmed and Iftikhar Ahmed Solangi: Reviewing and editing

Muhammad Noman Khan, Naila Ilyas and

Muhammad Bakhtiar: Review.

Memona Siddique: Introduction.

Mohamed E1-Fatieh Ismael: Analysis.

Wang Yunyang: Supervisor.

\section{Conflict of interest}

The authors have declared no conflict of interest.

\section{References}

Ambrak, A.R., T.J. Mason, L. Paniwnyk and V. Lelas. 2007. Accelerated drying of button mushrooms, Brussels sprouts and cauliflower by applying power ultrasound and its rehydration properties. J. Food Eng., 81: 88-97. https://doi. org/10.1016/j.jfoodeng.2006.10.009

AOAC DC, 1990. Official methods of analysis $15^{\text {th }}$ Ed.Association of Official Analytical Chemists, Washington.

Assis, F.R., R.M.S.C. Morais and A.M.M.B. Morais. 2016. Mass transfer in osmotic dehydration of food products: Comparison between mathematical models. Food Eng. Rev., 8: 116-133. https://doi.org/10.1007/s12393015-9123-1

Azarpazhooh and H.S. Ramaswamy. 2010. Evaluation of factors influencing microwave osmotic Dehydration of Apples under continuous Flow Medium. https://doi. org/10.1007/s11947-010-0446-x

Da Silva, A.F., Jr., W.P. da Silva, J.E. de Farias Aires, K.L.C.A.F. Aires and D.S. de Castro. 2017. Osmotic dehydration kinetics of banana slices considering variable di usivities and shrinkage. Int. J. Food Prop., 20: 1313-1325. 
Deng,Y.and Y.Zhao.2008. Effect of pulsed vacuum and ultrasound osmopretreatments on glass transition temperature, texture, microstructure and calcium penetration of dried apples (Fuji). LWT. Food Sci. Tech., 41: 15751585. https:// doi.org/10.1016/j.lwt.2007.10.018

Eshraghi, M. Lu, K. Nejad, M.B. Tousi and S.M. Alami. 2011. The study of effect of ultrasound pre-treatment on drying Kiwi slices. J. Sci. Res. Iran. Food Ind., 7(4): 273-279.

Ferrando, M. and W.E.L. Spiess. 2003. Mass transfer in strawberry tissue during osmotic treatment. J. Food Sci., 68: 1347-1364. https:// doi.org/10.1111/j.1365-2621.2003.tb09650.x

Ghorbani, R., J. Dehghan-Nia, S.S.L. Haris and B. Ghanbarzadeh. 2013. Modelling shrinkage of pre-treated plum by ultrasound and osmotic hydration in drying process. J. Agric. Mech., 58: 33-43.

Imam, J., Z. Tahmasebi, M.P. Fard and K. Asgari. 2008. The study of effect of osmotic pre-process on textural and micro-structural of dried tomato with air, engineering. J Iran Biosyst., pp. 133-139.

Iran National Standard 4404: $\mathrm{pH}$ measurement method in fruits and vegetables

Jambrak, A.R., T.J. Mason, L. Paniwnyk and V. Lelas. 2006. Accelerated drying of button. Mushrooms, Brussels sprouts and cauliflower by applying power ultrasound and its rehydration properties of Food Eng. https:// doi.org/10.1016/j.jfoodeng.2006.10.009

Maskouki, A., A. Mortazavi and A.V. Maskouki. 2007. The study of the combined effect of ultrasound waves and soda on reducing the drying time of grapes and producing raisin. J. Food Sci. Iran Food Ind. Year II, 5: 1 -10.

Moeini, S. and M. Javaheri. 2004. The study of application of osmosis method in drying Kilka fish. J. Iran Agric. Sci., 35(4): 901-909.

Mokhtar, W.M.F.W., S.K. Ghawi, K. Niranjan. 2019. Dehydration of potato slices following brief dipping in osmotic solutions: Effect of conditions and understanding the mechanism of water loss. Dry. Technol., 37: 885-895. https://doi.org/10.1080/07373937.2018.1473 418

Nieto, A.B., D.M. Salvatore, M.A. Castro and S.M. Alzamora. 2004. Structural changes in apple tissue during glucose and sucrose osmotic dehydration: Shrinkage, porosity, density and microscopic features. J. Food Eng., 61: 269-278. https://doi.org/10.1016/S02608774(03)00108-0

Nowacka, M., A. Wiktor, M. Śledź, N. Jurek and D. Witrowa-Rajchert. 2012. Drying of ultrasound pretreated apple and its selected physical properties. J. Food Eng., 113: 427-433. https:// doi.org/10.1016/j.jfoodeng.2012.06.013

Rene, F. and M. Marin. 2009. Process quality optimization of the vacuum freeze- drying of apple slices by the response surface method. Int. J. Food Sci. Tech., 34: 145-160. https://doi. org/10.1046/j.1365-2621.1999.00247.x

Rezagah, M.A., M.K. Nejad, H.A. MirzaeiI and M. Khamiri. 2009. The effect of temperature, density of osmotic solution and weight ratio on the kinetics of osmotic drying Agaricus bisporus. J. Agric. Sci. Natl. Resour., 25: 17911796.

Rodrigues, S. and F.A.N. Fernandes. 2007. Image analysis of osmotically dehydrated fruits: melons dehydration in a ternary system. J. Eur. Food Res. Technol., 225: 685-691. https://doi. org/10.1007/s00217-006-0466-y

Schossler, K., H. Jager and D. Knorr. 2012. Effect of continuous and intermittent ultrasound on drying time and effective diffusivity during convective drying of apple and red bell pepper. J. Food Eng., 108: 103-110. https://doi. org/10.1016/j.jfoodeng.2011.07.018

Seiiedlou, S., H.R. Ghasemzadeh, N. Hamdami, F.T.alati and M.Moghaddam. 2010. Convective drying of apple: mathematical modeling and determination of some quality parameters. Int. J. Agric. Biol., 12: 171-178.

Shahidi, F., M. Mohebbi, M. Nowshad, A. Ehtiyati and M. Fathi. 2011. The study of the effect of osmosis and ultrasound pre-treatment on some qualitative characteristics of dried banana by hot air method.J. Sci. Res. Iran. Food Ind., 7(4): 263-277.

Sioholm, I. and V. Gekas. 1995. Apple shrinkage upon during. J. Food Eng., 25: 123-130. https:// doi.org/10.1016/0260-8774(94)00001-P

Spiazzi, E. and R.R. Mascheroni. 1997. Mass transfer model for osmotic dehydration of fruits and vegetables. I. Development of the simulation model. J. Eng., 34: 387-341. https:// doi.org/10.1016/S0260-8774(97)00102-7

Sun,L.,H.Zhang and Y.Zhuang. 2012.Preparation of free, soluble conjugate and insoluble-bound 
phenolic compounds from peels of rambutan (Nephelium lappaceum) and evaluation of antioxidant activities in vitro. J. Food Sci., 77(2): C198-204. https://doi.org/10.1111/j.17503841.2011.02548.x

Torreggiani, D. and G. Bertolo. 2004. Present and future in process control and optimization of osmotic dehydration: From unit operation to innovative combined process: An overview. Adv. Food Nutr. Res. Elsevier Amsterdam, The Netherlands, 48: 173-238. https://doi. org/10.1016/S1043-4526(04)48004-8

Torreggiani, D., G. Bertolo. 2001. Osmotic pretreatments in fruit processing: Chemical, physical and structuraleects. J. Food Eng., 49: 247-253. https://doi.org/10.1016/S02608774(00)00210-7

Xiao, M.,J.Bi,J.Yi, Y.Zhao,J.Peng, L.Zhou and Q. Chen. 2019. Osmotic pretreatment for instant controlled pressure drop dried apple chips: Impact of the type of saccharides and treatment conditions. Dry. Technol., 37: 896-905. https:// doi.org/10.1080/07373937.2018.1473419

Zecchi, B. and P. Gerla. 2020. Effective diffusion coefficients and mass flux ratio during osmotic dehydration considering real shape and shrinkage. J. Food Eng., 274: 109821. https:// doi.org/10.1016/j.jfoodeng.2019.109821 